\title{
Antibacterial Mechanisms of Reduced Iron-containing Smectite-illite Clay Minerals
} Biogeology and Environmental Geology, China University of Geosciences, Beijing 100083, P.R.

6 China

\# Co-first author

*Corresponding author: Hailiang Dong

Geomicrobiology Laboratory, State Key Laboratory of Biogeology and Environmental Geology, dongh@cugb.edu.cn

Supporting information includes detailed information for: Chemicals, 1, 10-phenanthroline method, Ferrozine method, X-ray diffraction (XRD), Zeta potential measurements, Measurements of soluble and adsorbed elemental concentrations, $\bullet \mathrm{O}_{2}^{-}$and $\bullet \mathrm{OH}$ detection by $\mathrm{EPR}, \mathrm{H}_{2} \mathrm{O}_{2}$ concentration measurement, $\bullet \mathrm{OH}$ quantification, $\mathrm{Fe}(\mathrm{IV})$ quantification, Measurement of total oxidants, Scanning electron microscopy (SEM), LIVE/DEAD ${ }^{\mathrm{TM}}$ BacLight ${ }^{\mathrm{TM}}$ Bacterial Viability Kit, Lipid peroxidation MDA assay, Protein carbonylation quantification, 10 tables and 12 figures 23 with a total of 29 pages. 


\section{Section S1: Chemicals}

Chemicals including sodium benzoate (SB, 99\%), 2-(N-Morpholino) ethanesulfonic acid (MES, 99\%), sodium dithionite (85\%), (2,2,6,6-Tetramethyl-1-piperidinyl)oxidanyl (TEMPO), ferrous sulfate heptahydrate $\left(\mathrm{FeSO}_{4} \cdot 7 \mathrm{H}_{2} \mathrm{O}\right), 2$,4-dinitrophenylhydrazine (DNPH), formaldehyde (HCHO), were all purchased from Sigma-Aldrich. Methyl phenyl sulfoxide (PMSO), methyl phenyl sulfone $\left(\mathrm{PMSO}_{2}\right)$, and hydrogen peroxide $\left(\mathrm{H}_{2} \mathrm{O}_{2}\right)$ were supplied by Macklin Biochemical Technology, Shanghai, China. 2,7-dichlorodihydrofluorescein diacetate (DCFH-DA) and catalase were purchased from Beyotime Biotechnology, Shanghai, China.

\section{Section S2: Determination of Fe(II) and Total Fe by the 1,10-Phenanthroline Method}

$\mathrm{Fe}(\mathrm{II})$ and total Fe contents of reduced clay suspensions were determined by 1,10phenanthroline method. ${ }^{1}$ To measure Fe(II) content, $0.2 \mathrm{~mL}$ clay suspension was mixed with 3.6 $\mathrm{N} \mathrm{M} \mathrm{H}_{2} \mathrm{SO}_{4}(0.48 \mathrm{~mL})$ to prevent oxidation of Fe(II). Subsequently $0.04 \mathrm{~mL} \mathrm{HF} \mathrm{(40 \% ,} \mathrm{w/v)} \mathrm{and}$ $0.08 \mathrm{~mL} \mathrm{1,10-phenanthroline} \mathrm{regent}(10 \%)$ were added. 1,10-phenanthroline regent was prepared

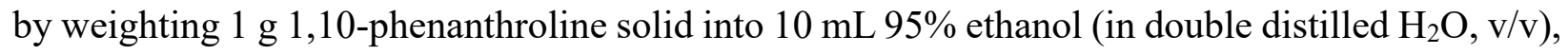
which was stored at $-20{ }^{\circ} \mathrm{C}$. The clay suspension was then boiled in a $100{ }^{\circ} \mathrm{C}$ water bath for 30 minutes to accelerate color development. After cooling for 15 minutes, $0.4 \mathrm{~mL} \mathrm{H}_{2} \mathrm{BO}_{3}$ was added to the mixture. Subsequently $0.1 \mathrm{~mL}$ of clay suspension was transferred into $1 \mathrm{~mL} \mathrm{Na-citrate}(1 \%$, w/v). After 20 minutes, Fe(II) content was determined by a UV-vis spectrophotometer (SHIMADZU2550, Japan) at $570 \mathrm{~nm}$ wavelength. Total Fe content was measured with the same procedure but after reduction of $\mathrm{Fe}(\mathrm{III})$ to $\mathrm{Fe}(\mathrm{II})$ by $10 \%$ hydroxylamine hydrochloride.

\section{Section S3: Determination of Soluble $\mathrm{Fe}^{2+}$ and Soluble Total $\mathrm{Fe}$ using Ferrozine Method}


Soluble $\mathrm{Fe}^{2+}$ and soluble total $\mathrm{Fe}$ were measured by using the Ferrozine method. ${ }^{2} 50 \mathrm{mM}$ HEPES buffer at $\mathrm{pH} 7$ was prepared, and $1 \mathrm{~g}$ ferrozine was dissolved into HEPES buffer to obtain the ferrozine regent. Clay suspensions were transferred and centrifuged to obtain supernatants. Then supernatants were filtered through a $0.22 \mu \mathrm{m}$ filter to obtain clear filtrates, followed by mixing with $1 \mathrm{M} \mathrm{HCl}$ at a ratio of $1: 1(\mathrm{v} / \mathrm{v}) .0 .1 \mathrm{~mL}$ mixture was added into $1 \mathrm{~mL}$ Ferrozine reagent followed by UV-vis spectrophotometric measurement at $562 \mathrm{~nm}$ wavelength. For total soluble Fe measurement, $\mathrm{Fe}(\mathrm{III})$ was first reduced by $10 \%$ hydroxylamine hydrochloride to $\mathrm{Fe}(\mathrm{II})$ followed by the same measurement.

\section{Section S4: Measurement of Soluble and Adsorbed Elements by Inductively Coupled Plasma-optical Emission Spectrometry (ICP-OES)}

Soluble and adsorbed elements may contribute to the antibacterial activity of clay minerals. Inductively coupled plasma-optical emission spectrometry (ICP-OES) was employed to measure the concentrations of soluble and adsorbed $\mathrm{Al}, \mathrm{Ca}, \mathrm{Fe}$, and $\mathrm{Si}$ leached from reduced S-I clay minerals. Suspensions of 5 reduced clays $[\sim 1.2 \mathrm{mM}$ initial total $\mathrm{Fe}(\mathrm{II})]$ in $10 \mathrm{mM} 2-(\mathrm{N}-$ Morpholino) ethanesulfonic acid (MES, $\mathrm{pH}$ 6) were prepared anaerobically and placed on a 150 rpm shaker. Five time points $(0,1,4,12$ and $24 \mathrm{~h})$ were selected. At each time point, clay suspensions of $1 \mathrm{~mL}$ in volume were centrifuged and filtered through a $0.22 \mu \mathrm{m}$ nylon filter, and supernatants were collected for analysis of soluble elements. For adsorbed elemental concentrations, clay pellets were resuspended in $1 \mathrm{~mL}$ oxalic acid-EDTA (Ox-EDTA) extraction mixture (18.6 g/L EDTA-Na2- $\mathrm{H}_{2} \mathrm{O}, 14.7 \mathrm{~g} / \mathrm{L}$ sodium citrate, $0.74 \mathrm{~g} / \mathrm{L} \mathrm{KCl}, 5 \mathrm{~g} / \mathrm{L} \mathrm{NaCl}$, and 12.6 $\mathrm{g} / \mathrm{L}$ oxalic acid, $\mathrm{pH} 8$ ) for $12 \mathrm{~h}$, followed by filtering through a $0.22 \mu \mathrm{m}$ nylon filter, and measured with ICP-OES. 


\section{Section S5: Measurement of Zeta Potentials}

The surface electrostatic potentials of clay minerals and E. coli cells, reflected by zeta potentials, are one of the factors that affect the interaction between clays and bacterial cells. Suspensions of 5 reduced clay suspensions $[\sim 0.12 \mathrm{mM}$ initial Fe(II) content $]$ in $1 \mathrm{mM} \mathrm{MES}$ at $\mathrm{pH}$ 6 were prepared at room temperature for zeta potential measurements with a zeta potential analyzer (Zeta PALS; Brookhaven Instruments). ${ }^{3}$ Zeta potential of E. coli cell surface was also measured.

\section{Section S6: X-Ray Diffraction (XRD)}

Around $0.5 \mathrm{~mL}$ of 5 chemically reduced clay suspensions were separately smeared onto petrographic slides and dried in a glove box. ${ }^{4}$ Identical aliquots were first oxidized in the air for $24 \mathrm{~h}$ and then prepared in the same way. XRD patterns were collected for reduced and oxidized clay minerals with a Rigaku Smart lab X-ray powder diffractometer equipped with $\mathrm{CuK} \alpha$ radiation at power of $9000 \mathrm{~W}(200 \mathrm{kV}, 45 \mathrm{~mA})$. All slides were scanned over the 2-theta range of 2 to $15^{\circ}$ with a counting time of $1 \mathrm{~s}$ per step of $0.02^{\circ}$.

\section{Section S7: Measurements of $\mathrm{H}_{2} \mathrm{O}_{2}$ Concentration}

$\mathrm{H}_{2} \mathrm{O}_{2}$ concentration was measured as previously reported. ${ }^{5,6}$ Clay suspensions with $\sim 1.2 \mathrm{mM}$ initial Fe(II) content were prepared as described above. At specific time points, clay suspensions were filtered by a $0.22 \mu \mathrm{m}$ filter, and $0.2 \mathrm{~mL}$ filtrate was mixed with the following regents: $20 \mu \mathrm{L}$ bipyridine (BPY, $20 \mathrm{mM}$ in $\left.1 \mathrm{mM} \mathrm{HClO}_{4}\right), 10 \mu \mathrm{L} \mathrm{Na}$-EDTA $(100 \mathrm{mM})$, and $40 \mu \mathrm{L}$ phosphate buffer (0.5 M at pH 6). After 1 minute, $2 \mu \mathrm{L}$ N,N-diethylphenylenediamine (DPD, $1 \%$ in $0.1 \mathrm{M}$ $\mathrm{H}_{2} \mathrm{SO}_{4}$ ) and $1 \mu \mathrm{L}$ horseradish peroxidase (POD, $100 \mathrm{U} / \mathrm{mL}$ ) regents were added. After 2 minute reaction, absorbance at $551 \mathrm{~nm}$ was measured using a $\mathrm{UV}$-vis spectrophotometer. $\mathrm{H}_{2} \mathrm{O}_{2}$ with known concentrations were prepared for establishing the standard curve (in a range of $1-100 \mu \mathrm{M}, \mathrm{R}^{2} \geqslant$ 
0.999).

\section{Section S8: •OH Quantification}

$\cdot \mathrm{OH}$ production from diluted clay mineral suspensions $[\sim 1.2 \mathrm{mM}$ initial $\mathrm{Fe}(\mathrm{II})$ content $]$ was measured after its reaction with $30 \mathrm{mM}$ sodium benzoate (SB) for 24 hours. The oxidation products of SB include three monohydroxybenzoic acids (4-hydroxybenzoic acid, 4-HBA; 3hydroxybenzoic acid, 3-HBA; salicylic acid, 2-HBA) and one dihydroxybenzoic acid (2,5-DHBA). Concentrations of these products in filtrates were analyzed with a Shimadzu HPLC (LC-20AT) equipped with a SPDM20A UV/Vis diode array detector, a fluorescence detector (RF-20A), and a C18 column (Agilent ZORBAX Eclipse Plus, $4.6 \times 150 \mathrm{~mm}, 5 \mu \mathrm{m}){ }^{7}$ The working solution consisted of $0.1 \%$ trifluoroacetic acid (mobile phase A) and acetonitrile (mobile phase B). Separation of the four possible products was made possible by the following gradient elution procedure: 0-13 $\min , 10 \% \mathrm{~B} ; 13-15 \mathrm{~min}, 10-30 \% \mathrm{~B} ; 15-23 \mathrm{~min}, 30 \% \mathrm{~B} ; 23-25 \mathrm{~min}, 30-60 \% \mathrm{~B}$; 25-30 $\min , 60 \%$ B; 30-31 min, 60-100\% B; 31-35 min, $100 \%$ B; 35-36 min, $100-10 \%$ B; 36-40 min, 10\% B. 4-HBA, 2,5-DHBA, 3-HBA and 2-HBA were eluted at 8.2, 11.5, 13.4 and 24.0 min, respectively. The detection wavelengths for 4-HBA, 2,5-DHBA, and 3-HBA were set at $276 \mathrm{~nm}$, $330 \mathrm{~nm}$ and $300 \mathrm{~nm}$, respectively. 2-HBA was measured by a fluorescence detector $(\lambda \mathrm{ex}=314 \mathrm{~nm}$, $\lambda \mathrm{em}=400 \mathrm{~nm})$. The cumulative concentration of $\bullet \mathrm{OH}$ was calculated as:

$$
[\bullet \mathrm{OH}]=[4-\mathrm{HBA}]+[3-\mathrm{HBA}]+[2-\mathrm{HBA}]+2 *[2,5-\mathrm{DHBA}]
$$

Four pure hydroxybenzoic acids were used for establishing the standard curves in the range of $0.2-50 \mu \mathrm{M}$ with a linear regression $\left(\mathrm{R}^{2} \geqslant 0.999\right)$.

\section{Section S9: Quantification of Fe(IV) from phenylmethyl sulfoxide (PMSO) oxidation}


At near-neutral $\mathrm{pH}$ condition, alternative oxidants such as high-valent iron species [e.g., $112 \mathrm{Fe}(\mathrm{IV})]$ can be produced upon oxidation of Fe(II) via Fenton reactions. ${ }^{8,9}$ Therefore, phenylmethyl 113 sulfoxide (PMSO) was utilized as a probe compound to measure the concentration of Fe(IV) since 114 PMSO could be oxidized to phenylmethyl sulfodioxide $\left(\mathrm{PMSO}_{2}\right)$ through a specific single oxygen 115 transfer mechanism. ${ }^{10,11}$ PMSO (4 mM, final conc.) was initially mixed with reduced clay minerals 116 ( $1.2 \mathrm{mM}$ initial Fe(II) conc.) and MES buffer (10 mM, final conc.) in cylindrical glass bottles. 117 All bottles were then placed in a $37^{\circ} \mathrm{C}$ incubator with constant shaking at $150 \mathrm{rpm} / \mathrm{min}$ at dark. At 118 selected time points, $0.5 \mathrm{~mL}$ filtrates were collected for the following detections. $\mathrm{PMSO}_{2}$ was quantified by a Shimadzu HPLC (LC-20AT) equipped with a SPDM20A UV/Vis diode array detector using a C18 column (Agilent ZORBAX Eclipse Plus, 4.6×150 mm, $5 \mu \mathrm{m}$ ). The working solution consisted of 80:20 mobile phase A (deionized water):mobile phase B (acetonitrile) at a flow rate of $0.8 \mathrm{~mL} / \mathrm{min}$. The wavelength for quantifying $\mathrm{PMSO}_{2}$ was $215 \mathrm{~nm}$. The content of $123 \mathrm{Fe}(\mathrm{IV})$ was calculated by the $\Delta \mathrm{PMSO}_{2}$ :

$$
\left[\Delta \mathrm{PMSO}_{2}\right]=\left[\mathrm{PMSO}_{2}\right]_{\mathrm{t}}-\left[\mathrm{PMSO}_{2}\right]_{0}
$$

where the $\left[\mathrm{PMSO}_{2}\right]_{\mathrm{t}}$ is the concentration of $\mathrm{PMSO}_{2}$ measured at time $\mathrm{t}$; the $\left[\mathrm{PMSO}_{2}\right]_{0}$ is the concentration of $\mathrm{PMSO}_{2}$ measured at time 0. Pure $\mathrm{PMSO}_{2}$ was utilized for establishing the standard 127 curve $(10-100 \mu \mathrm{M})$ by using the linear regression $\left(\mathrm{R}^{2} \geqslant 0.999\right)$.

\section{Section S10: Measurement of Total Oxidants}

To further evaluate the production of ROS and possible weak oxidants, total oxidants were 130 quantified by measuring the concentration of $\mathrm{HCHO}$, produced from oxidation of methanol. HCHO was determined by using 2,4-dinitrophenylhydrazine (DNPH) derivatization to HCHO132 DNPH since HCHO-DNPH was more stable and easier than HCHO for quantification. DNPH 
133

134

135

136

137

138

139

140

141

142

143

144

145

146

147

148

149

150

151

152

153

154

solution, the derivatizing reagent, was first prepared by dissolving $25 \mathrm{mg}$ recrystallized DNPH in $10 \mathrm{~mL} 12 \mathrm{~N} \mathrm{HCl}$. Reduced S-I clay minerals (initial total Fe(II) conc. at $\sim 1.2 \mathrm{mM}$ ) were mixed with MES buffer (5 mM, final conc.) and methanol (125 mM, final conc.) in cylindrical glass bottles. All bottles were placed in a $37{ }^{\circ} \mathrm{C}$ incubator, with constant shaking at $150 \mathrm{rpm} / \mathrm{min}$ and loosely sealed for air exchange. At selected time points, samples were collected and filtered through a $0.22 \mu \mathrm{m}$ nylon filter. $0.5 \mathrm{~mL}$ filtrates were immediately mixed with $4 \mu \mathrm{L}$ of derivatizing reagent, followed by incubation for 1 hour at $37^{\circ} \mathrm{C}$. The concentration of accumulated total oxidants was obtained by measuring the concentration of DNPH-HCHO, whose concentration was the same as HCHO.

DNPH-HCHO was quantified with a Shimadzu HPLC (LC-20AT) equipped with a SPDM20A UV/Vis diode array detector, a fluorescence detector (RF-20A), and a C18 column (Agilent ZORBAX Eclipse Plus, $4.6 \times 150 \mathrm{~mm}, 5 \mu \mathrm{m})$. The working solution consisted of $60 \% 0.1 \%$ trifluoroacetic acid (mobile phase A) and 40\% acetonitrile (mobile phase B) at a flow rate of 1 $\mathrm{mL} / \mathrm{min}$, and the HCHO-DNPH was quantified at $365 \mathrm{~nm}$. The standard curve was established by using pure $\mathrm{HCHO}$ with the same derivatizing procedure in a range of $5-200 \mu \mathrm{M}\left(\mathrm{R}^{2} \geqslant 0.999\right)$.

Section S11: $\bullet_{2}^{-}$and $\bullet \mathrm{OH}$ Detection by Electron Paramagnetic Resonance (EPR) Spectroscopy

$\cdot \mathrm{O}_{2}{ }^{-}$and $\bullet \mathrm{OH}$ were also detected by electron paramagnetic resonance (EPR) spectroscopy. For the detection of $\bullet \mathrm{OH}$, five S-I clay suspensions $[\sim 1.2 \mathrm{mM}$ initial total $\mathrm{Fe}(\mathrm{II})]$ in $10 \mathrm{mM}$ MES buffer (pH 6) were individually mixed with 5,5-dimethyl-1-pyrrolidine-N-oxide (DMPO) in water (20 mM, final conc.) inside a glove box. The mixture was then oxidized in air for $10 \mathrm{~min}$ and measured on a Bruker A300-10/12 EPR spectrometer under the following conditions: microwave 
155 frequency $=9.852 \mathrm{GHz}$, microwave power $=19.02 \mathrm{~mW}$, receiver gain $=1.0 \times 10^{3}$, modulation 156 frequency $=100 \mathrm{kHz}$, modulation amplitude $=1.0 \mathrm{G}$, center field $=3510 \mathrm{G}$, sweep width $=100 \mathrm{G}$, 157 and sweep time $=20.97 \mathrm{~s}$. DMPO in methanol was instead utilized for the detection of $\bullet \mathrm{O}_{2}{ }^{-}$under 158 the same conditions.

159

160

161

162

163

164

165

166

167

168

169

170

171

172

173

174

175

176

\section{Section S12: Scanning Electron Microscopy (SEM)}

The morphological changes of $E$. coli cells were detected with scanning electron microscopy (SEM). After $4 \mathrm{~h}$ air exposure, E. coli-clay suspensions were prepared for SEM observation according to our previously published protocols. ${ }^{3,12}$ Several droplets of mixtures were dropped on a Poly-L-lysine coated glass coverslip. Then mixtures were fixed with $2 \%$ paraformaldehyde and 2.5\% glutaraldehyde, followed by rinsing in PBS buffer ( $\mathrm{pH}$ 7.2) three times and gradient dehydration with ethanol $(25 \%$ - 100\%). Samples were subsequently dried with a Quorum K850 Critical Point Dryer (CPD) and coated with a Quorum SC7620 Sputter Coater. Finally, treated mixtures were subjected to SEM observations under the accelerating voltage of $3 \mathrm{kV}$ and a working distance of $15 \mathrm{~cm}$.

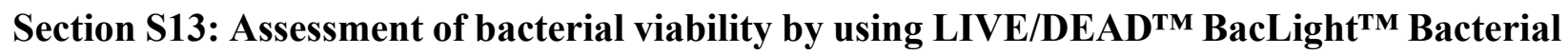
Viability Kit

LIVE/DEAD ${ }^{\mathrm{TM}}$ BacLight $^{\mathrm{TM}}$ Bacterial Viability Kit, which is a mixture of nucleic acidbinding stains of SYTO $9^{\mathrm{TM}}$ and propidium iodide, was used to visually assess bacterial viability of $E$. coli cells after treatments of S-I clay minerals. Initially, a $2 \mathrm{X}$ staining reagent was prepared by dissolving one unit of Component A (SYTO 9 nucleic acid stain) and one unit of Component B

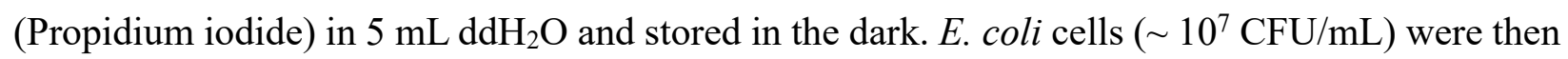
incubated with S-I clay minerals $[\sim 1.2 \mathrm{mM}$ initial total $\mathrm{Fe}(\mathrm{II})]$ in air for $4 \mathrm{~h}$. Then clay-treated $E$. 
177 coli cells were mixed with staining reagent $(1: 1, \mathrm{v} / \mathrm{v})$, and the mixture was reacted in the dark for 17815 min. Finally, E.coli cells were observed by using an epifluorescence microscopy (Olympus, 179 BX51 equipped with a DP71 digital camera, Tokyo, Japan) .

180

181

182

183

184

185

186

187

188

189

190

191

192

193

194

195

196

197

198

\section{Section S14: Lipid Peroxidation Malondialdehyde (MDA) Assay}

The level of membrane lipid peroxidation was measured by using the MDA Assay Kit (Beyotime Biotechnology, Shanghai, China) due to the relative stability of MDA after membrane oxidation. BCA Protein Assay Kit (Beyotime Biotechnology, Shanghai, China) was also used to quantify protein and calculate the final MDA concentration. Five S-I clay suspensions $[\sim 1.2 \mathrm{mM}$ $\mathrm{Fe}(\mathrm{II})$ content] were prepared, mixed with $E$. coli cells, and incubated with air in a $150 \mathrm{rpm}$ shaker. Then mixtures were collected after $4 \mathrm{~h}$ treatment and the concentration was measured according to the manufacturer's protocol. The final MDA concentration was expressed as MDA ( $\mu$ mol) per unit of protein $(\mathrm{mg})$.

\section{Section S15: Protein Carbonylation Quantification}

The protein carbonyl content reflects the level of protein oxidation. ${ }^{13}$ In this study, membranebound and soluble proteins after clay treatments were extracted by using the Membrane and Cytosol Protein Extraction Kit (Beyotime Biotechnology, Shanghai, China) according to the manufacturer's protocol. The clay-bacteria mixtures were prepared in the same manner as described for the MDA measurement (Section S13). At each time point, mixtures were transferred for protein carbonyl concentration measurement using the Protein Carbonyl Content Assay Kit purchased from Sigma-Aldrich. The protein content was also measured by BCA Protein Assay Kit

(Beyotime Biotechnology, Shanghai, China). The protein carbonyl content was expressed as carbonyl (nmol) per unit of protein (mg). 
Table S1 Clay mineral characterization

\begin{tabular}{|c|c|c|c|c|c|}
\hline \multirow[b]{2}{*}{ Experiments } & \multicolumn{4}{|c|}{ Experimental components } & \multirow{2}{*}{$\begin{array}{l}\text { Corresponding } \\
\text { figure/table }\end{array}$} \\
\hline & $\begin{array}{c}\text { Unreduced } \\
\text { Clay }\end{array}$ & Reduced Clay & E. coli & Scavenger & \\
\hline XRD pattern & - & $\begin{array}{c}\text { rRAr-1/ rNAu-2/ } \\
\text { rSWy-3/ rISCz-1/ rIMt-2 }\end{array}$ & - & - & Figure S1 \\
\hline $\begin{array}{l}\text { Zeta potential } \\
\text { measurement }\end{array}$ & - & $\begin{array}{c}\text { rRAr-1/ rNAu-2/ } \\
\text { rSWy-3/ rISCz-1/ rIMt-2 } \\
-\end{array}$ & $\begin{array}{l}- \\
+\end{array}$ & - & Table S5 \\
\hline $\begin{array}{l}\text { Measurements for soluble } \\
\text { and adsorbed metals }\end{array}$ & - & $\begin{array}{c}\text { rRAr-1/ rNAu-2/ } \\
\text { rSWy-3/ rISCz-1/ rIMt-2 }\end{array}$ & - & - & Table S6 \\
\hline $\begin{array}{l}\text { EPR detection for } \\
\cdot \mathrm{OH} \text { and } \bullet \mathrm{O}_{2}^{-}\end{array}$ & - & $\begin{array}{c}\text { rRAr-1/ rNAu-2/ } \\
\text { rSWy-3/ rISCz-1/ rIMt-2 }\end{array}$ & - & - & Figure S4 \\
\hline Determination of $\mathrm{H}_{2} \mathrm{O}_{2}$ & - & $\begin{array}{c}\text { rRAr-1/ rNAu-2/ } \\
\text { rSWy-3/ rISCz-1/ rIMt-2 }\end{array}$ & - & - & Figure S5 \\
\hline $\begin{array}{c}\text { Quantification of } \bullet \mathrm{OH}, \\
\mathrm{Fe}(\mathrm{IV}) \text { and total oxidations }\end{array}$ & - & $\begin{array}{c}\text { rRAr-1/ rNAu-2/ } \\
\text { rSWy-3/ rISCz-1/ rIMt-2 }\end{array}$ & - & $\begin{array}{c}\text { SB (40 mM, for } \bullet \mathrm{OH}) \\
\text { PMSO (4 mM, for } \mathrm{Fe}(\mathrm{IV})) \\
\text { Methanol (125 mM, for } \\
\text { total oxidations) }\end{array}$ & Figures 1 \\
\hline
\end{tabular}


Table S2 Experimental conditions for the antibacterial susceptibility assay

\begin{tabular}{|c|c|c|c|c|c|c|c|c|c|}
\hline & \multicolumn{8}{|c|}{ Experimental components } & \multirow{2}{*}{$\begin{array}{c}\text { Corresponding } \\
\text { figure/table }\end{array}$} \\
\hline & Unreduced Clay & Reduced Clay & $\begin{array}{c}E . \\
\text { coli }\end{array}$ & $\begin{array}{l}\text { Aqueous } \\
\mathrm{Fe}^{2+}(\mu \mathrm{M})\end{array}$ & $\begin{array}{l}\mathrm{H}_{2} \mathrm{O}_{2} \\
(\mu \mathrm{M})\end{array}$ & $\begin{array}{l}\mathrm{Al}^{3+} \\
(\mu \mathrm{M})\end{array}$ & Scavenger & $\begin{array}{l}\text { Air/ } \\
\mathrm{N}_{2}\end{array}$ & \\
\hline Experimental & - & $\begin{array}{c}\text { rRAr-1/ rNAu-2/ } \\
\text { rSWy-3/ rISCz-1/ } \\
\text { rIMt-2 }\end{array}$ & + & - & - & - & - & Air & Figure 3A \\
\hline \multirow{7}{*}{ Controls } & $\begin{array}{c}\text { RAr-1/ NAu-2/ } \\
\text { SWy-3/ ISCz-1/ } \\
\text { IMt-2 }\end{array}$ & $\begin{array}{c}- \\
\text { rRAr-1/ rNAu-2/ } \\
\text { rSWy-3/ rISCz-1/ } \\
\text { rIMt-2 }\end{array}$ & + & - & - & - & - & Air & Figure S8A \\
\hline & - & $\begin{array}{c}\text { rRAr-1/ rNAu-2 } \\
\text { /rSWy-3 }\end{array}$ & + & - & - & - & $\begin{array}{c}\mathrm{SB} / \\
\text { Catalase/ } \\
\text { TEMPO }\end{array}$ & Air & Figure $3 \mathrm{C}$ \\
\hline & - & - & + & $60 \sim 360$ & - & - & - & Air & \\
\hline & - & - & + & - & $12 \sim 100$ & - & - & Air & \\
\hline & - & - & + & - & - & 250 & - & Air & Figure S8B \\
\hline & - & - & + & $60 \sim 360$ & $12 \sim 80$ & - & - & Air & \\
\hline & - & - & + & 280 & - & - & - & $\mathrm{N}_{2}$ & \\
\hline
\end{tabular}


Note: All experiments were conducted at pH 6 in $10 \mathrm{mM}$ MES buffer with an initial E. coli concentration of $10^{8} \mathrm{CFU} / \mathrm{mL}$. Initial Fe(II) concentration was set up at

$\sim 1.2 \mathrm{mM}$ for each clay suspension. To control the initial Fe(II) content at $\sim 1.2 \mathrm{mM}$, clay mass concentrations varied in the S-I series: rNAu-2 (0.55 g/L), rRAr-1

Table S3 Characterization of clay-treated E. coli cells

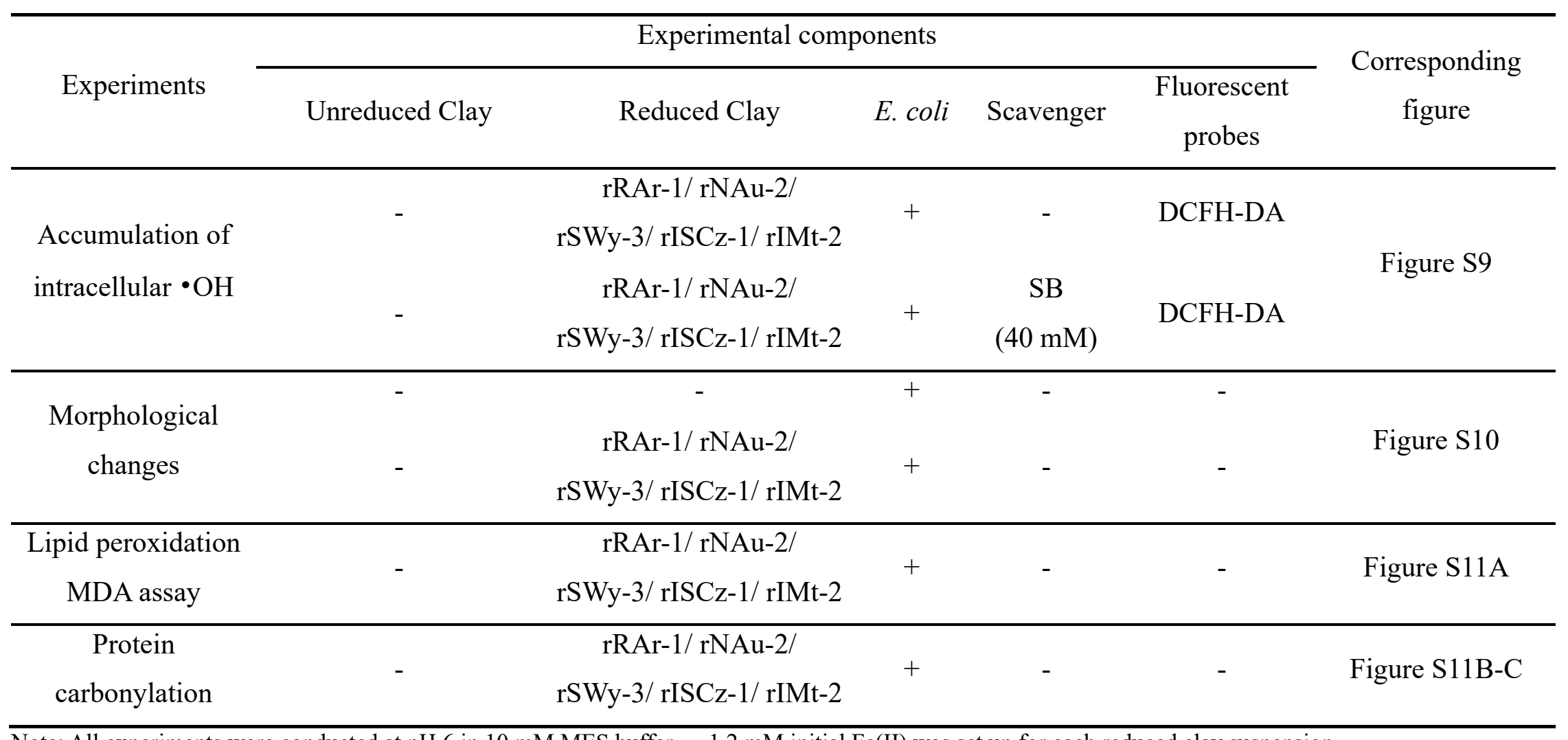


Table S4 Total Fe content and reduction extent for S-I clay minerals

\begin{tabular}{cccccc}
\hline & \multicolumn{5}{c}{ Clay minerals } \\
\cline { 2 - 6 } & rRAr-1 & rSWy-3 & rNAu-2 & rISCz-1 & rIMt-2 \\
\hline Total Fe content (wt.\%) & 4.9 & 2.3 & 21.2 & 0.7 & 12.3 \\
Reduction extent (\%) & 89.4 & 68.9 & 73.8 & 44.1 & 19.2
\end{tabular}

211

212

213

214

215

216

Note: Total Fe content (wt.\%) was retrieved from previously published papers. ${ }^{14}$ Reduction extents for reduced S-I

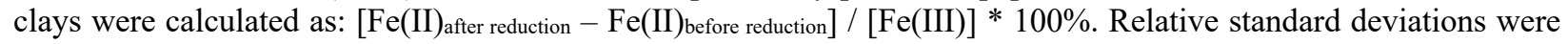
less than $10 \%$.

Table S5 Zeta potential, BET specific area (SA), and total surface area for reduced clay minerals and $E$. coli cells

\begin{tabular}{cccc}
\hline Clay & $\begin{array}{c}\text { Zeta potential } \\
(\mathrm{mV})\end{array}$ & $\begin{array}{c}\text { BET SA (retrieved from published } \\
\left.\text { works, }{ }^{14} \mathrm{~m}^{2} / \mathrm{g}\right)\end{array}$ & $\begin{array}{c}\text { Total surface area** } \\
\left(\mathrm{m}^{2}\right)\end{array}$ \\
\hline rRAr-1 & -39.24 & 144 & 0.58 \\
$\mathrm{rSWy}-3$ & -35.52 & 240 & 2.74 \\
$\mathrm{rNAu}-2$ & -33.64 & 271 & 0.30 \\
$\mathrm{rISCz}-1$ & -42.33 & 129 & 7.74 \\
$\mathrm{rIMt}-2$ & -47.96 & 5 & 0.05 \\
E. coli & -38.40 & $\mathrm{NM}$ & $\mathrm{NM}$ \\
\hline
\end{tabular}

Note: ${ }^{*}$ : Average zeta potentials were measured and calculated from triplicate measurements with relative standard deviations less than 5\%. NM: Not measured. **: Total surface area is calculated as follows: Total surface area $=$ BET $\mathrm{SA} *$ clay mass concentration * total volume used $(2 \mathrm{~mL})$. Clay mass concentration was retrieved from Table S2. 
222 Table S6 Variations of soluble and adsorbed elements from reduced S-I clay minerals over the 223 course of 24 hour air oxidation [1.2 mM initial Fe(II)] at pH 6

\begin{tabular}{|c|c|c|c|c|c|c|c|c|c|}
\hline \multirow[t]{2}{*}{ Time (h) } & \multirow[t]{2}{*}{ Clay } & \multicolumn{4}{|c|}{ Soluble Concentration $(\mu \mathrm{M})$} & \multicolumn{4}{|c|}{ Adsorbed Concentration $(\mu \mathrm{M})$} \\
\hline & & $\mathrm{Al}$ & $\mathrm{Ca}$ & $\mathrm{Fe}$ & $\mathrm{Si}$ & $\mathrm{Al}$ & $\mathrm{Ca}$ & $\mathrm{Fe}$ & $\mathrm{Si}$ \\
\hline \multirow{5}{*}{0} & rRAr-1 & 1.18 & 16.58 & 30.61 & 216.40 & 12.29 & 50.95 & 76.35 & 171.10 \\
\hline & rSWy-3 & 254.93 & 19.04 & 39.56 & 737.17 & 11.70 & 66.47 & 39.84 & 206.66 \\
\hline & rNAu-2 & 1.22 & 22.77 & 9.30 & 534.93 & 5.58 & 40.91 & 22.04 & 179.29 \\
\hline & rISCz-1 & 123.94 & 236.56 & 6.03 & 1893.19 & 10.34 & 159.39 & 4.48 & 260.60 \\
\hline & rIMt-2 & 7.77 & 17.26 & 2.97 & 362.39 & 4.98 & 65.80 & 17.09 & 158.91 \\
\hline \multirow{5}{*}{1} & rRAr-1 & 1.22 & 70.56 & 257.20 & 390.40 & 14.46 & 35.91 & 198.83 & 92.25 \\
\hline & rSWy-3 & 3.48 & 7.54 & 2.91 & 634.26 & 18.24 & 111.16 & 81.07 & 111.93 \\
\hline & rNAu-2 & 0.75 & 37.90 & 30.57 & 545.54 & 13.99 & 53.22 & 51.47 & 110.00 \\
\hline & rISCz-1 & 0.66 & 221.95 & 0.85 & 1840.96 & 18.84 & 102.82 & 4.82 & 183.76 \\
\hline & rIMt-2 & 58.40 & 19.30 & 12.87 & 477.79 & 5.65 & 73.65 & 18.78 & 81.46 \\
\hline \multirow{5}{*}{4} & rRAr-1 & 2.55 & 53.98 & 88.14 & 353.24 & 12.22 & 42.41 & 167.63 & 112.97 \\
\hline & rSWy-3 & 2.26 & 13.30 & 5.38 & 614.40 & 18.47 & 54.06 & 104.78 & 162.77 \\
\hline & rNAu-2 & 5.21 & 40.21 & 65.66 & 578.01 & 23.58 & 121.91 & 42.59 & 174.00 \\
\hline & rISCz-1 & 1.64 & 253.59 & 1.12 & 1738.39 & 13.99 & 86.87 & 48.63 & 112.53 \\
\hline & rIMt-2 & 12.34 & 16.20 & 8.74 & 378.35 & 10.41 & 61.45 & 36.04 & 107.71 \\
\hline \multirow{5}{*}{12} & rRAr-1 & 1.63 & 38.12 & 26.95 & 343.64 & 8.16 & 39.52 & 89.84 & 107.80 \\
\hline & rSWy-3 & 1.20 & 1.94 & 8.52 & 607.14 & 13.44 & 73.22 & 60.40 & 153.65 \\
\hline & rNAu-2 & 10.51 & 29.98 & 106.74 & 687.72 & 18.53 & 111.59 & 69.29 & 160.99 \\
\hline & rISCz-1 & 3.26 & 220.78 & 0.84 & 1817.75 & 11.96 & 91.18 & 70.09 & 113.26 \\
\hline & rIMt-2 & 27.86 & 9.05 & 8.12 & 421.99 & 8.66 & 62.32 & 30.03 & 107.54 \\
\hline \multirow{5}{*}{24} & rRAr-1 & 4.27 & 34.07 & 2.89 & 352.68 & 6.63 & 51.35 & 75.53 & 103.86 \\
\hline & rSWy-3 & 11.05 & 4.53 & 7.76 & 642.19 & 17.56 & 102.62 & 66.05 & 133.71 \\
\hline & rNAu-2 & 7.08 & 42.85 & 17.09 & 652.79 & 6.00 & 49.77 & 21.47 & 104.03 \\
\hline & rISCz-1 & 108.6 & 228.83 & 26.32 & 3023.44 & 8.68 & 197.66 & 4.28 & 165.96 \\
\hline & rIMt-2 & 58.01 & 20.07 & 10.86 & 476.56 & 4.29 & 79.98 & 12.39 & 88.82 \\
\hline
\end{tabular}


228 Table $\mathbf{S} 7 \mathrm{Fe}(\mathrm{II})$ consumption, $\bullet \mathrm{OH}$ production, and $\bullet \mathrm{OH}$ generation efficiency $[\bullet \mathrm{OH} / \Delta \mathrm{Fe}(\mathrm{II})]$

$229(\mu \mathrm{M} / \mathrm{mM})$ for reduced S-I clay minerals

\begin{tabular}{cccc}
\hline & $\Delta \mathrm{Fe}(\mathrm{II})(\mathrm{mM})$ & Total $\bullet \mathrm{OH}$ Produced $(\mu \mathrm{M})$ & $\bullet \mathrm{OH} / \Delta \mathrm{Fe}(\mathrm{II})(\mu \mathrm{M} / \mathrm{mM})$ \\
\hline rRAr-1 & 0.67 & 26.85 & 40.07 \\
rSWy-3 & 0.73 & 22.45 & 30.50 \\
rNAu-2 & 0.72 & 16.68 & 23.13 \\
rISCz-1 & 0.13 & 1.10 & 8.43 \\
rIMt-2 & 0.16 & 0.85 & 5.66
\end{tabular}

230

231

232

233

234

235

236

Note: $\Delta \mathrm{Fe}(\mathrm{II})$ refers to the amount of $\mathrm{Fe}(\mathrm{II})$ oxidized [e.g., $\mathrm{Fe}(\mathrm{II})$ initial $-\mathrm{Fe}(\mathrm{II})$ residual] after $24 \mathrm{~h}$ air oxidation.
Measurements were conducted at $\mathrm{pH} 6$ in $10 \mathrm{mM}$ MES with $\sim 1.2 \mathrm{mM}$ initial $\mathrm{Fe}(\mathrm{II})$.

Table S8 Fe(II) consumption, $\mathrm{PMSO}_{2}$ production, and generation efficiency of ferryl iron [Fe(IV) / $\Delta \mathrm{Fe}(\mathrm{II})](\mu \mathrm{M} / \mathrm{mM})$ for reduced S-I clay minerals

\begin{tabular}{cccc}
\hline & $\Delta \mathrm{Fe}(\mathrm{II})(\mathrm{mM})$ & $\mathrm{PMSO}_{2}(\mathrm{Fe}(\mathrm{IV}))$ Produced $(\mu \mathrm{M})$ & $\mathrm{PMSO}_{2} / \Delta \mathrm{Fe}(\mathrm{II})(\mu \mathrm{M} / \mathrm{mM})$ \\
\hline rRAr-1 & 0.80 & 16.92 & 21.25 \\
rSWy-3 & 0.69 & 5.30 & 7.68 \\
rNAu-2 & 0.84 & 6.10 & 7.26 \\
rISCz-1 & 0.15 & 0.01 & 0.06 \\
rIMt-2 & 0.16 & 0.01 & 0.06 \\
\hline
\end{tabular}

Note: $\Delta \mathrm{Fe}(\mathrm{II})$ refers to the amount of $\mathrm{Fe}(\mathrm{II})$ oxidized [e.g., $\mathrm{Fe}(\mathrm{II})_{\text {initial }}-\mathrm{Fe}(\mathrm{II})_{\text {residual] }}$ after $24 \mathrm{~h}$ air oxidation. Measurements were conducted at pH 6 in $10 \mathrm{mM}$ MES with $\sim 1.2 \mathrm{mM}$ initial Fe(II). 
240 Table S9 Fe(II) consumption, HCHO production, and generation efficiency of total oxidants

$241[\mathrm{HCHO} / \Delta \mathrm{Fe}(\mathrm{II})](\mu \mathrm{M} / \mathrm{mM})$ for reduced S-I clay minerals

\begin{tabular}{cccc}
\hline & $\Delta \mathrm{Fe}(\mathrm{II})(\mathrm{mM})$ & $\begin{array}{c}\text { HCHO (total oxidants) } \\
\text { Produced }(\mu \mathrm{M})\end{array}$ & $\begin{array}{c}\mathrm{HCHO} / \Delta \mathrm{Fe}(\mathrm{II}) \\
(\mu \mathrm{M} / \mathrm{mM})\end{array}$ \\
\hline rRAr-1 & 0.73 & 169.39 & 232.04 \\
rSWy-3 & 0.58 & 80.96 & 139.58 \\
rNAu-2 & 0.79 & 103.68 & 131.24 \\
rISCz-1 & 0.18 & 15.23 & 84.60 \\
rIMt-2 & 0.19 & 7.18 & 37.79 \\
\hline
\end{tabular}

Note: $\Delta \mathrm{Fe}(\mathrm{II})$ refers to the amount of $\mathrm{Fe}(\mathrm{II})$ oxidized [e.g., $\mathrm{Fe}(\mathrm{II})_{\text {initial }}-\mathrm{Fe}(\mathrm{II})_{\text {residual] }}$ after $24 \mathrm{~h}$ air oxidation.

Table S10 Bactericidal efficiency within the initial $2 \mathrm{~h}$ after cell treatments with rRAr-1, rSWy-3 and $\mathrm{rNAu}-2$

\begin{tabular}{cccc}
\hline & $\begin{array}{c}\text { Cell number decrease } \\
\text { (Order of magnitude) }\end{array}$ & \multicolumn{2}{c}{ Rate of cell number decrease } \\
\cline { 3 - 4 } & 1.50 & Slope $(\mathrm{K})$ & $\mathrm{R}^{2}$ \\
\hline rRAr-1 & 0.41 & -0.691 & 0.841 \\
rSWy-3 & 0.86 & -0.204 & 0.982 \\
rNAu-2 & -0.442 & 0.844 \\
\hline
\end{tabular}



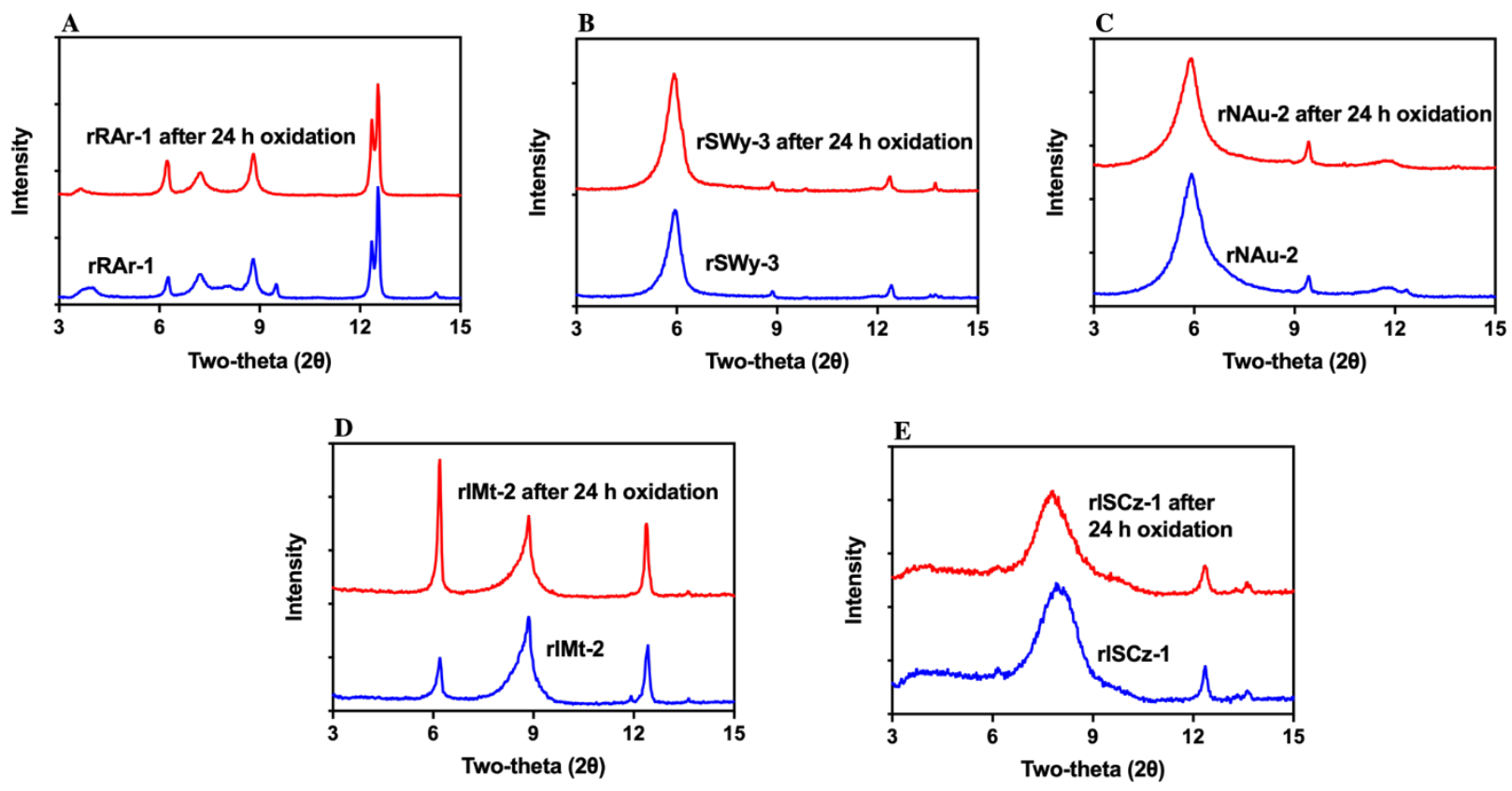

252 Figure S1 Comparisons of XRD patterns before and after 24 hour air oxidation at pH 6 for (A)

253 rRAr-1, (B) rSWy-3, (C) rNAu-2, (D) rIMt-2 and (E) rISCz-1. No obvious changes were observed 254 after $24 \mathrm{~h}$ air exposure.
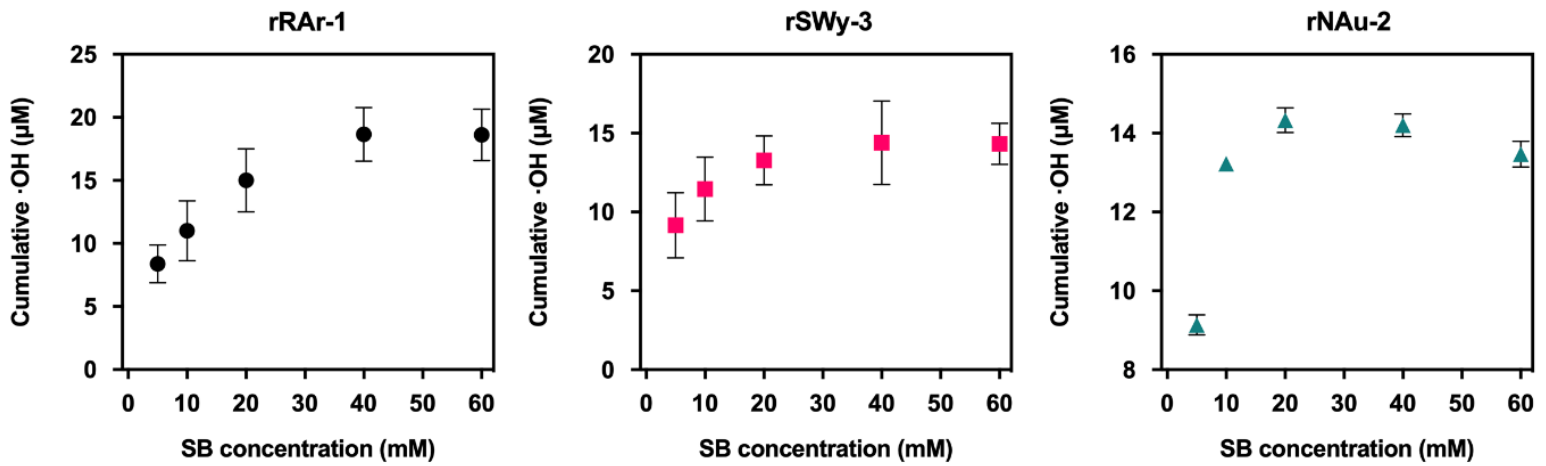

257 Figure S2 $\cdot \mathrm{OH}$ quantification by a concentration gradient of sodium benzoate (SB) in rRAr-1,

258 rSWy-3, and rNAu-2. SB concentration: from $5 \mathrm{mM}$ to $60 \mathrm{mM}$. Initial total $\mathrm{Fe}(\mathrm{II})$ concentration: $259 \quad 1.2 \mathrm{mM}$. 


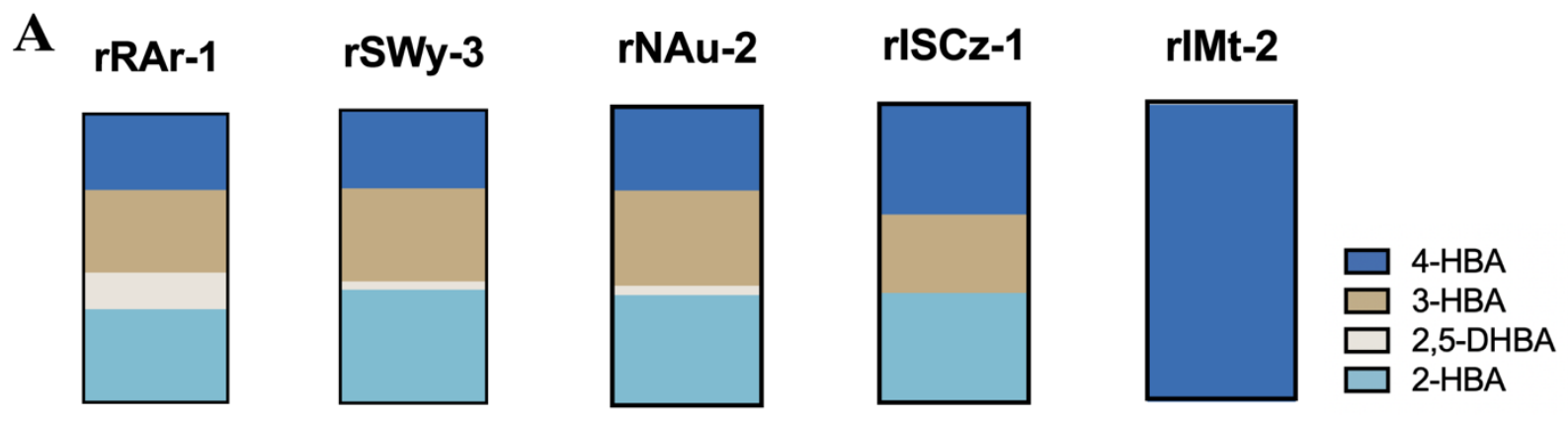

Total $=23.12$ Total $=\mathbf{2 1 . 8 2}$ Total $=16.17 \quad$ Total $=\mathbf{0 . 3 1}$ Total $=\mathbf{3 . 6 1}$
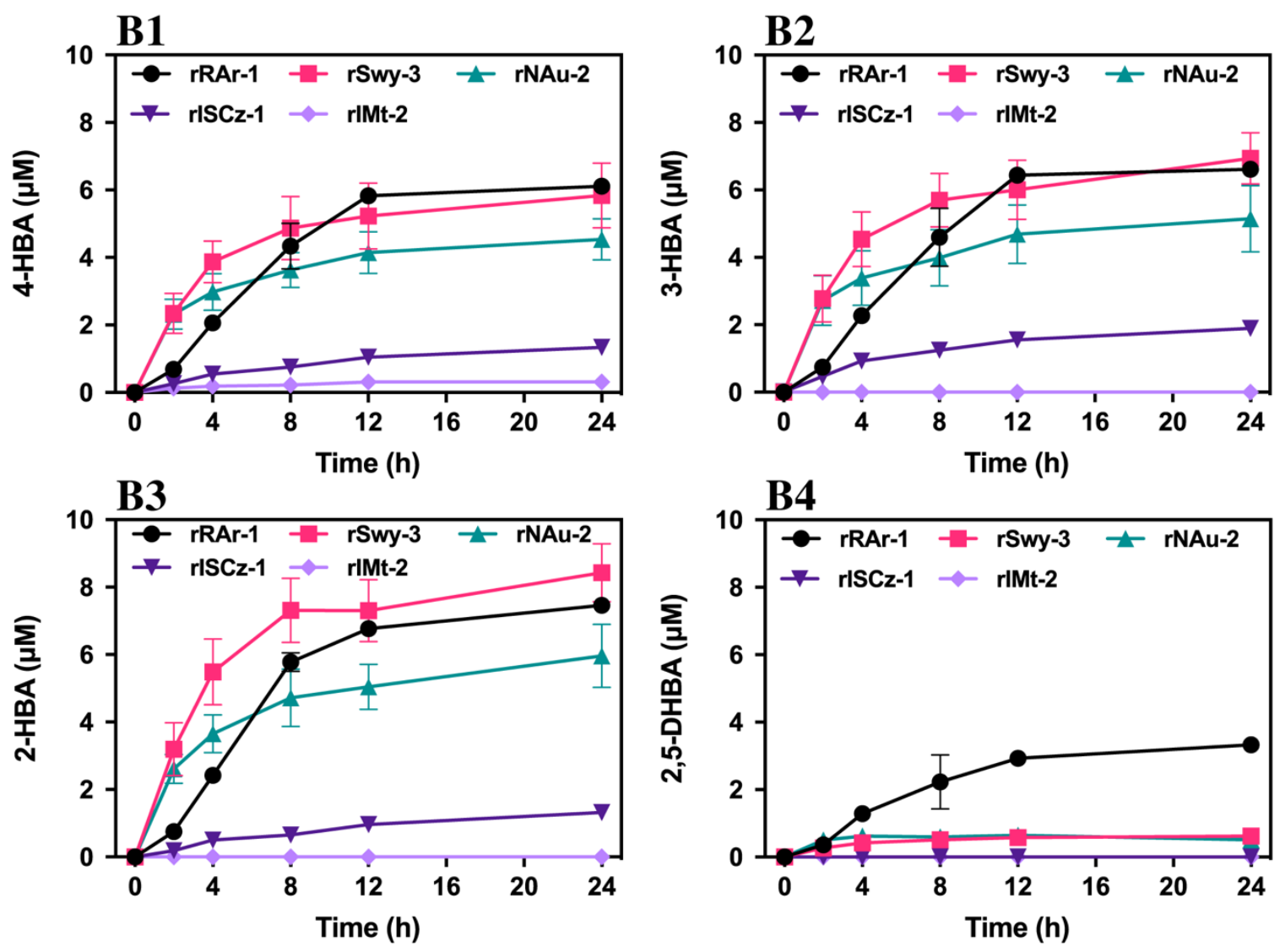

263

264 Figure S3 (A) Four major oxidation products of sodium benzoate by clay-generated $\bullet \mathrm{OH}$ at the 265 end of 24 hours. The sum of these products (i.e., cumulative $\bullet \mathrm{OH}$ ) was the highest in rRAr- 1 , with 266 a high fraction of 2,5-DHBA. (B1-B4) Time-course production of (B1) 4-HBA, (B2) 3-HBA, (B3) 267 2-HBA and (B4) 2,5-DHBA by five reduced S-I clay suspensions at pH 6 [initial Fe(II) 268 concentration at $\sim 1.2 \mathrm{mM}]$. All error bars represent standard deviation from triplicate experiments. 

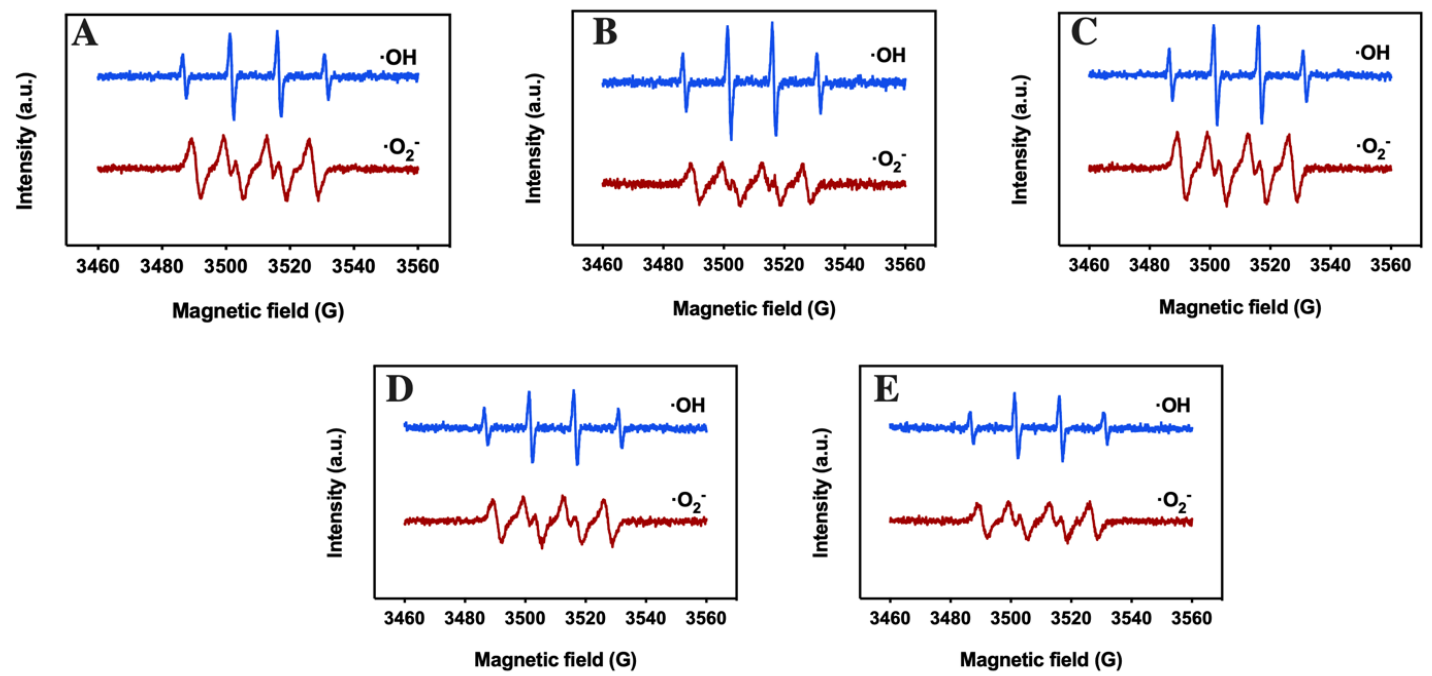

270 Figure S4 EPR detection of $\bullet \mathrm{O}_{2}^{-}$and $\bullet \mathrm{OH}$ in (A) rRAr-1, (B) rSWy-3, (C) rNAu-2, (D) rIMt-2

271 and (E) $\mathrm{rISCz}-1$. EPR spectra for $\bullet \mathrm{O}_{2}{ }^{-}$generation were indicated by the red color and $\bullet \mathrm{OH}$ by the 272 blue color. The typical $\bullet \mathrm{O}_{2}{ }^{-}$and $\bullet \mathrm{OH}$ EPR patterns were observed, demonstrating that S-I clay 273 minerals were capable of generating these radicals. 


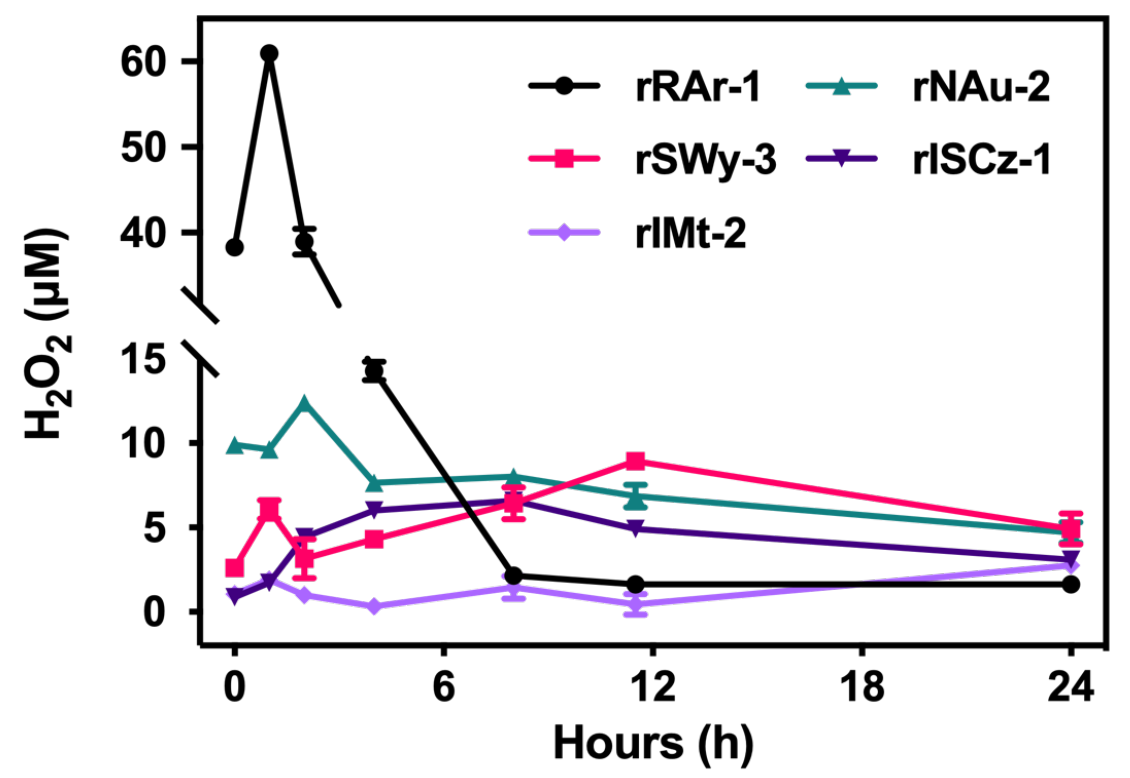

275 Figure S5 Time-course production of $\mathrm{H}_{2} \mathrm{O}_{2}$ by reduced S-I clay minerals upon air exposure for 24

276 h. Experiments were conducted at pH 6 in 10 mM MES buffer. Initial total Fe(II) concentration

277 was set as $\sim 1.2 \mathrm{mM}$ for all clay suspensions. Error bars represent standard deviation from triplicate

278 experiments. Some error bars are smaller than the symbol sizes and therefore not visible. 

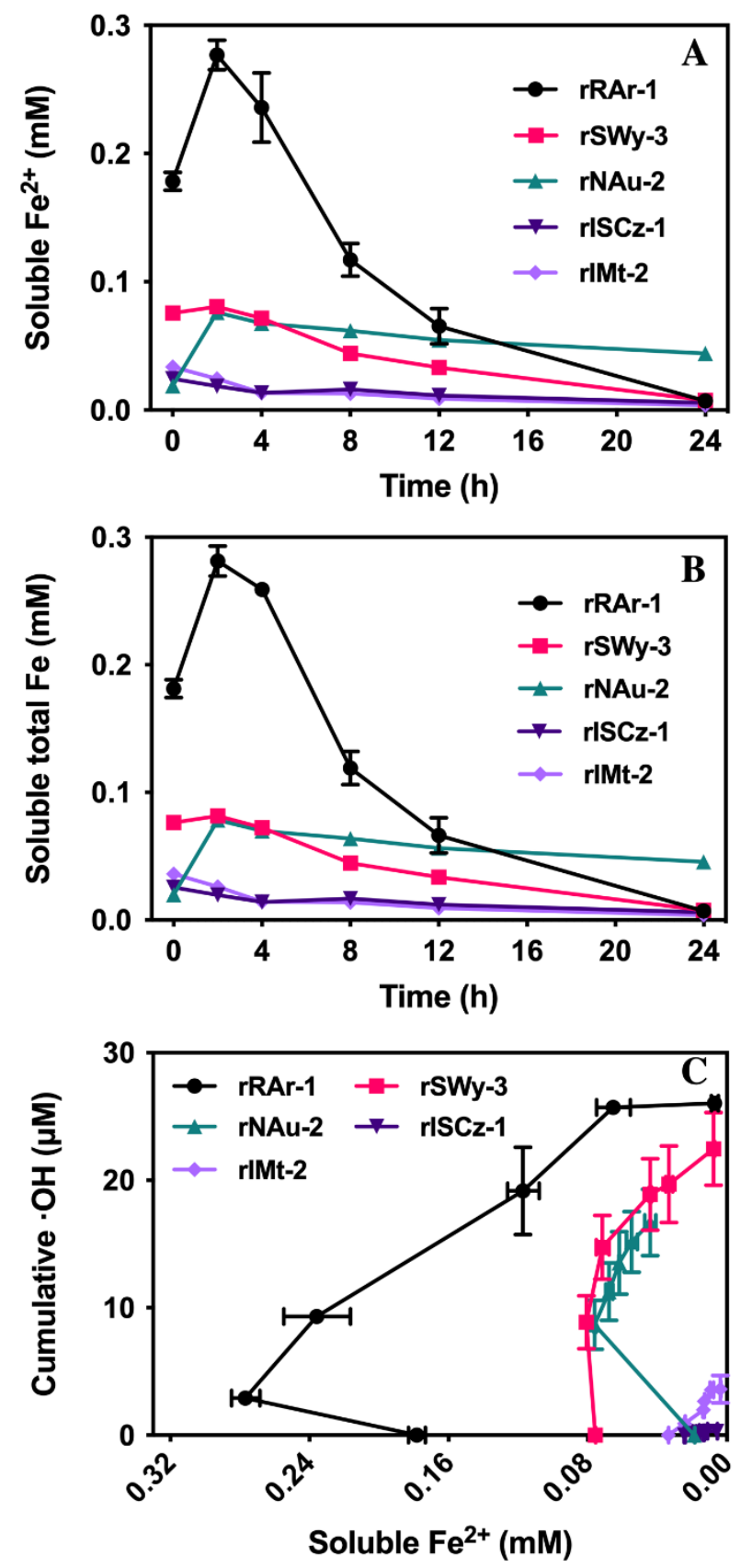

280 Figure S6 Time-course variations of (A) soluble $\mathrm{Fe}^{2+}$ and (B) soluble total Fe for S-I clay 281 suspensions with an initial total $\mathrm{Fe}(\mathrm{II})$ of $1.2 \mathrm{mM}$ at $\mathrm{pH}$ 6. (C) A positive correlation was observed 282 between soluble $\mathrm{Fe}^{2+}$ oxidation and total $\bullet \mathrm{OH}$ production after removal of the first time point where $283 \cdot \mathrm{OH}$ production may be limited by clay dissolution. Error bars represent standard deviation from 284 duplicate experiments. 

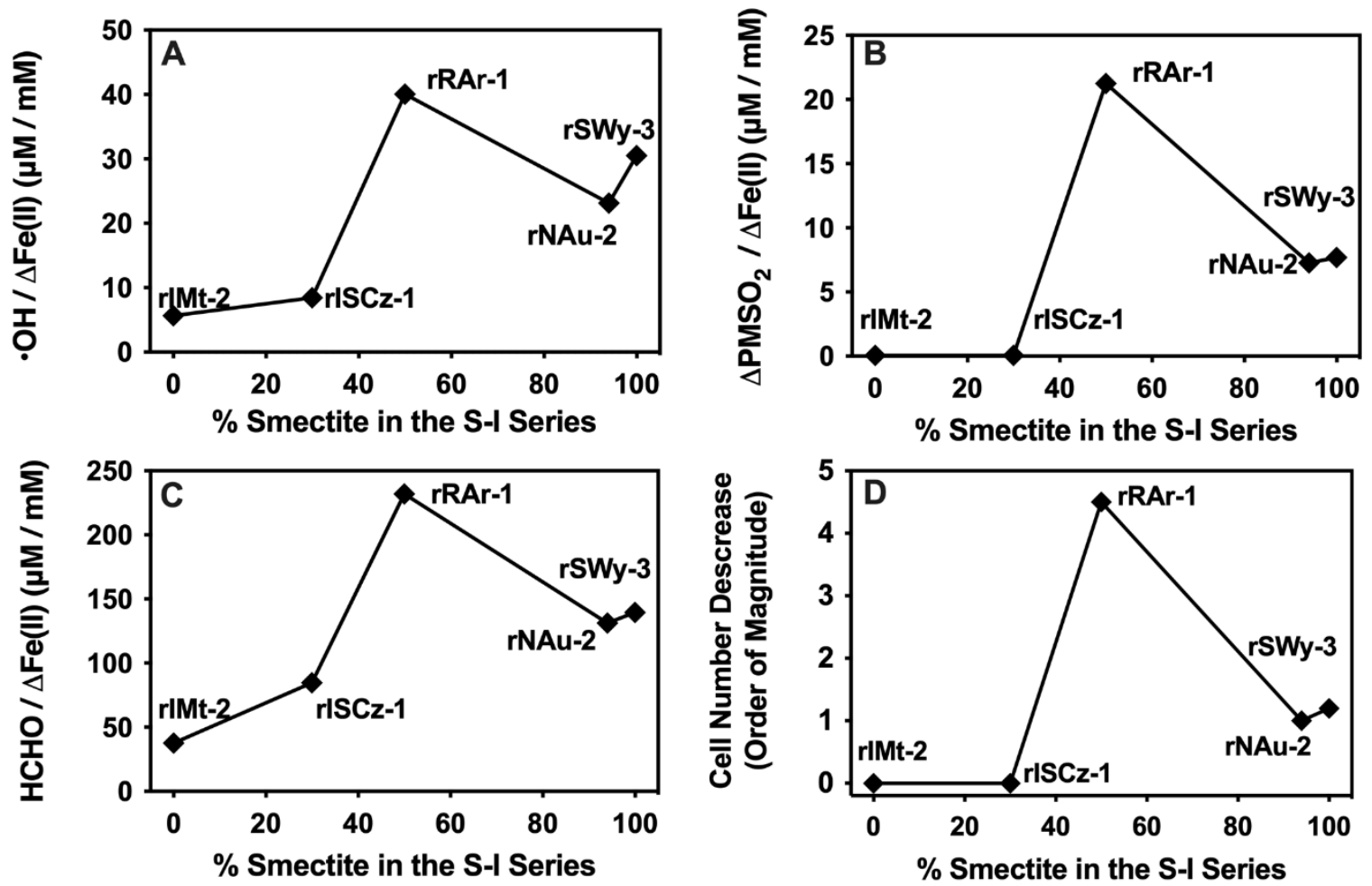

286 Figure S7 No correlations between \% smectite in the S-I series and oxidant production efficiency.

287 (A) $\bullet \mathrm{OH}$ production efficiency retrieved from Table $\mathrm{S} 7$; (B) generation efficiency of $\mathrm{PMSO}_{2}$, 288 retrieved from Table S8; (C) total oxidant generation efficiency, retrieved from Table S9; (D) CFU 289 decrease, retrieved from Figure $3 \mathrm{~A} . \Delta \mathrm{Fe}(\mathrm{II})=\mathrm{Fe}(\mathrm{II})_{\text {initial }}-\mathrm{Fe}(\mathrm{II})_{\text {residue }}$, where $\mathrm{Fe}(\mathrm{II})_{\text {initial }}$ represents 290 the concentration of $\mathrm{Fe}(\mathrm{II})$ at time 0 , and $\mathrm{Fe}(\mathrm{II})$ residue refers to the content of $\mathrm{Fe}(\mathrm{II})$ at $24 \mathrm{~h}$. 


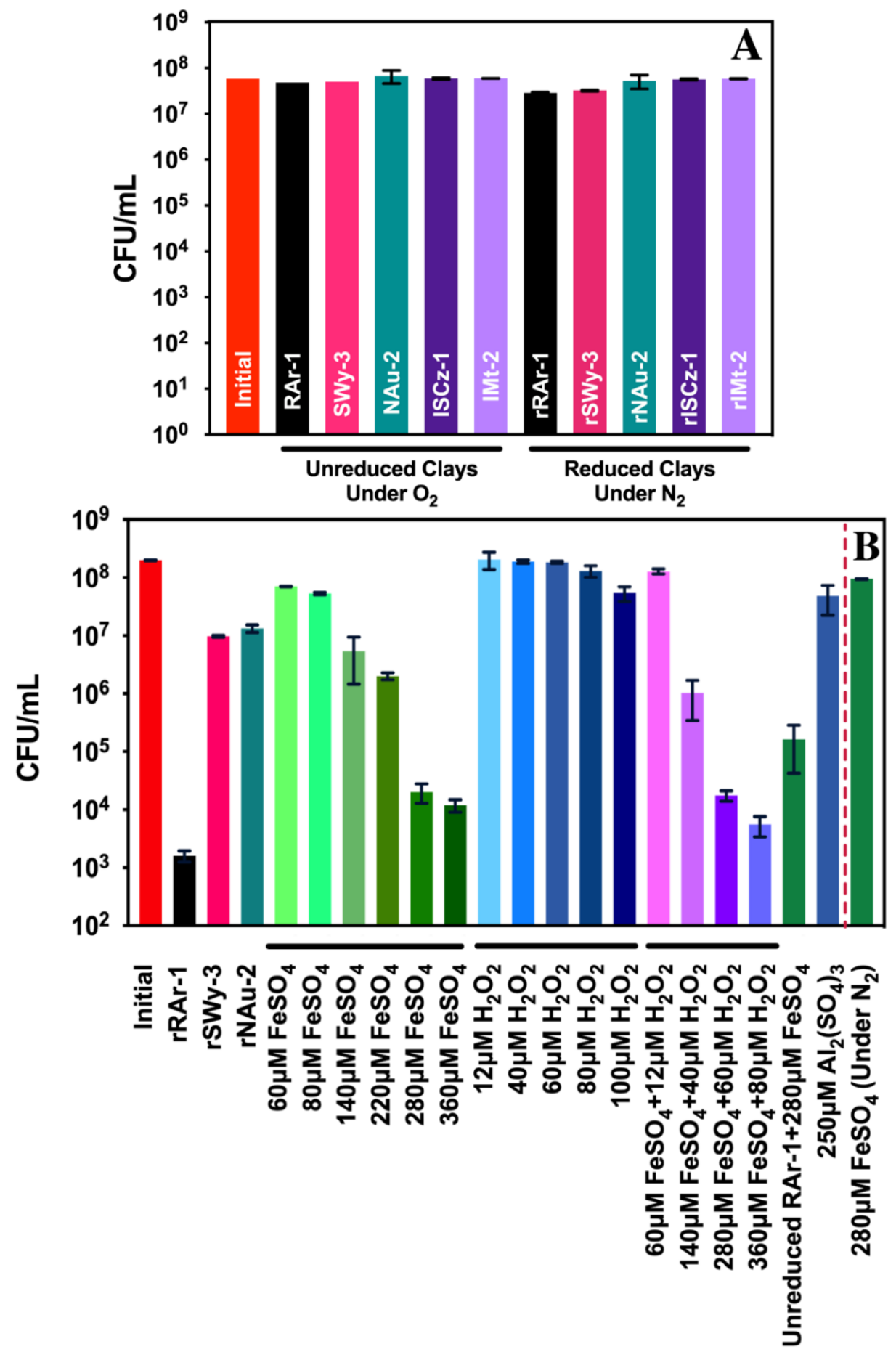

294 Figure S8 (A) Change of E. coli cell counts after exposure of unreduced S-I minerals to air and 295 reduced S-I minerals to $\mathrm{N}_{2}$. Measured $\mathrm{pH}$ change was less than 0.1 unit during $24 \mathrm{~h}$ air oxidation, 296 and error bars represent standard deviation from triplicate experiments. (B) CFU changes of $E$. 
297 coli cells in $10 \mathrm{mM}$ MES after $24 \mathrm{~h}$ air exposure to $\mathrm{FeSO}_{4} \bullet 7 \mathrm{H}_{2} \mathrm{O}, \mathrm{H}_{2} \mathrm{O}_{2}$, and $\mathrm{FeSO}_{4} \bullet 7 \mathrm{H}_{2} \mathrm{O}+\mathrm{H}_{2} \mathrm{O}_{2}$. 298 Gradient concentrations of $\mathrm{FeSO}_{4} \cdot 7 \mathrm{H}_{2} \mathrm{O}$ and $\mathrm{H}_{2} \mathrm{O}_{2}$ in the control experiments were used. Those 299 concentrations were determined based on the measured values of soluble $\mathrm{Fe}^{2+}$ and $\mathrm{H}_{2} \mathrm{O}_{2}$ in rRAr$3001, \mathrm{rSWy}-3$ and rNAu-2 antibacterial experiments (Figure S5). CFU data for E. coli cells exposed 301 to $280 \mu \mathrm{M} \mathrm{FeSO}{ }_{4} \cdot 7 \mathrm{H}_{2} \mathrm{O}+$ unreduced RAr-1 in oxic environment, $250 \mu \mathrm{M} \mathrm{Al}_{2}\left(\mathrm{SO}_{4}\right)_{3}$, and $280 \mu \mathrm{M}$ $302 \mathrm{FeSO}_{4} \bullet 7 \mathrm{H}_{2} \mathrm{O}$ in $\mathrm{N}_{2}$ atmosphere were also included for comparison. In all cases, measured $\mathrm{pH}$ 303 changes were less than 0.1 unit, and error bars represent standard deviation from triplicate 304 experiments. 

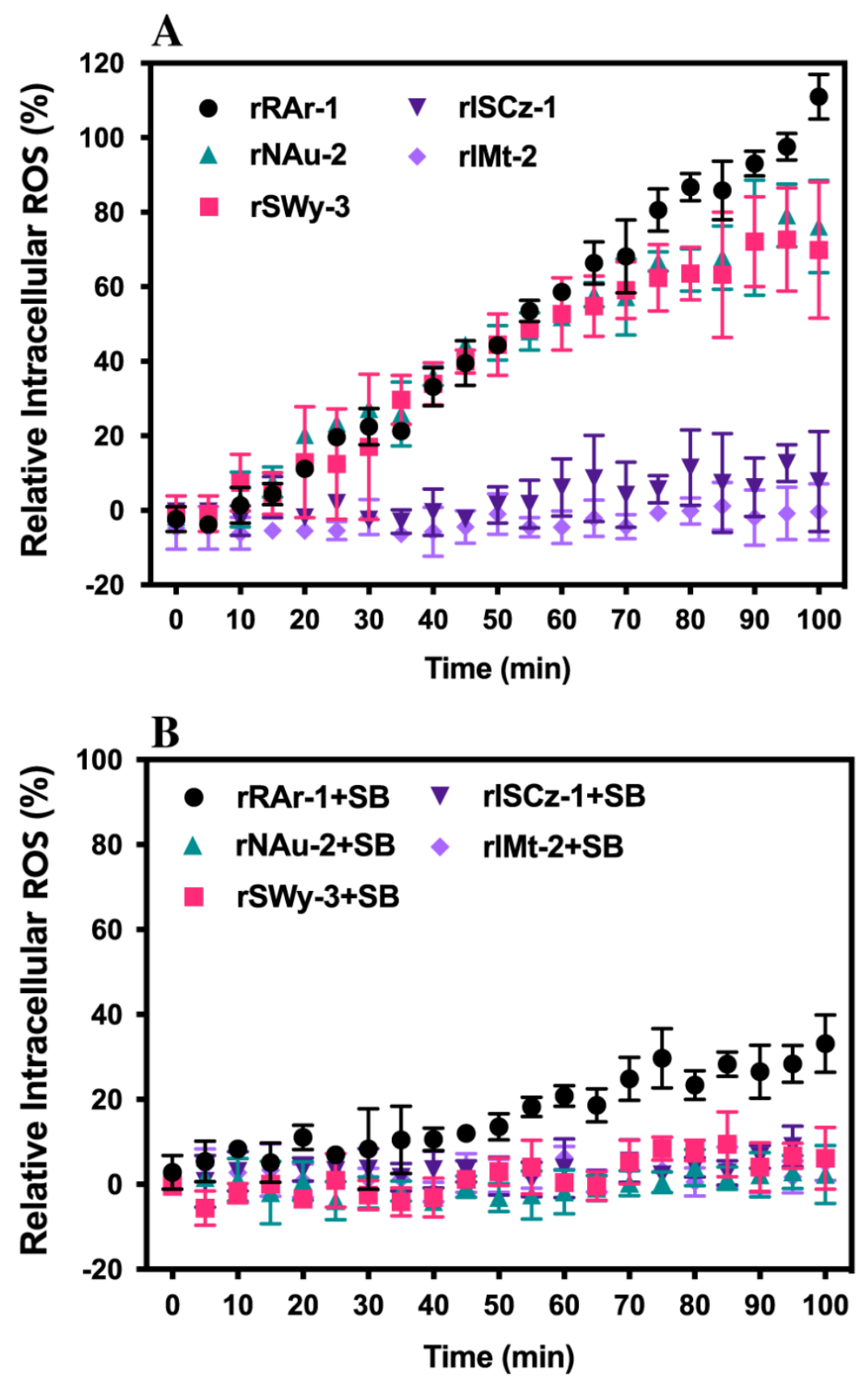

305 Figure S9 (A) Intracellular $\bullet \mathrm{OH}$ accumulation after exposure to reduced S-I clay minerals for 100 $306 \mathrm{~min}$ in air [Initial total $\mathrm{Fe}(\mathrm{II})$ concentration was set up at $\sim 1.2 \mathrm{mM}$ for each clay] at $\mathrm{pH} 6$ in $1 \mathrm{mM}$ 307 MES. (B) Corresponding intracellular $\cdot \mathrm{OH}$ accumulation in the presence of $4 \mathrm{mM}$ sodium 308 benzoate. Error bars represent standard deviation from four independent measurements. 

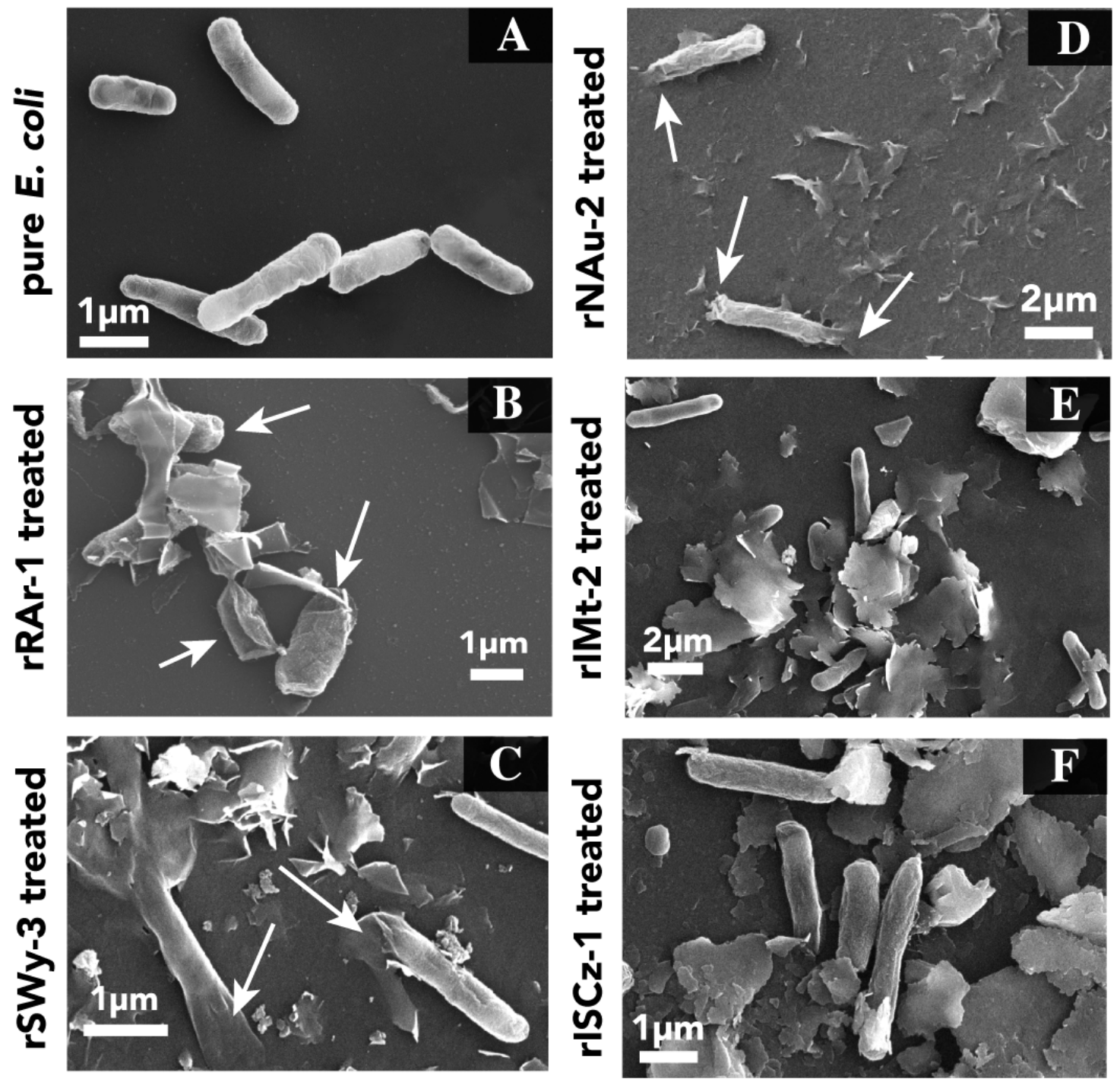

Figure S10 SEM images of $E$. coli cells after $4 \mathrm{~h}$ exposure to reduced S-I clay minerals $[\sim 1.2 \mathrm{mM}$

310 initial $\mathrm{Fe}(\mathrm{II})$ concentration] at pH 6 in $1 \mathrm{mM}$ MES. Relative to (A) the pure culture, morphologies

311 of $E$. coli cells were barely altered after exposure to (B) rIMt-2 and (C) rISCz-1, while more severe

312 membrane disruptions of $E$. coli cell polar regions were observed after exposure to (D) rRAr-1, (E)

313 rSWy-3, and (F) rNAu-2 (white arrows). 

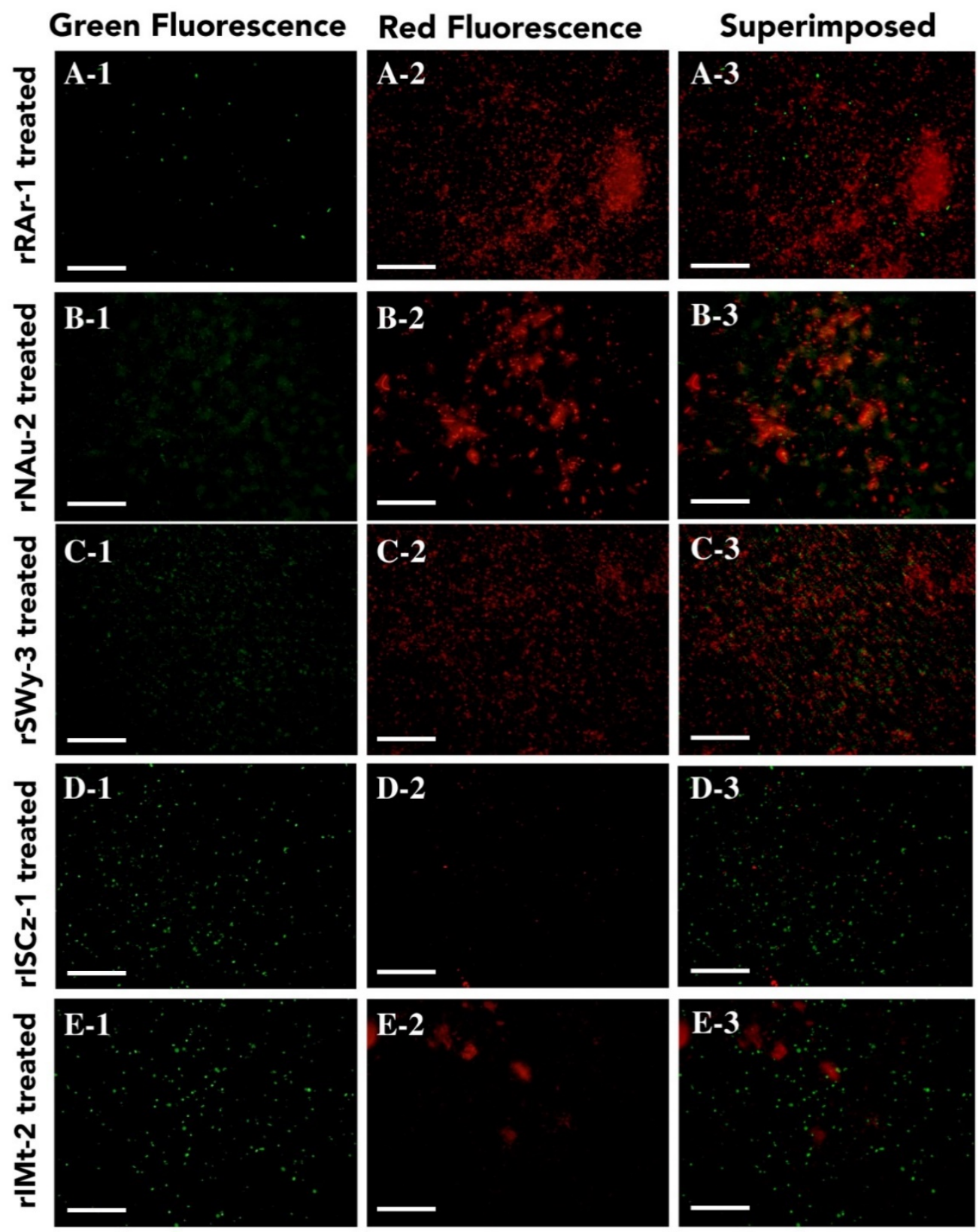

315 Figure S11 Cell viability test by using LIVE/DEAD BacLight staining in the presence of S-I clay

316 minerals. For cells incubated with (A) rRAr-1, (B) rNAu-2, and (C) rSWy-3, a pattern with a weak

317 green (live, A-1 \& B-1 \& C-1) and strong red fluorescence (dead, A-2 \& B-2 \& C-2) was observed,

318 indicating that cells were dead. As for E.coli cells treated with (D) rISCz-1 and (E) rIMt-2, a strong

319 green (live, D-1 \& E-1) and weak red fluorescence (dead, D-2 \& E-2) was visualized, which revealed that cells were still alive. All scale bars are $100 \mu \mathrm{m}$. 

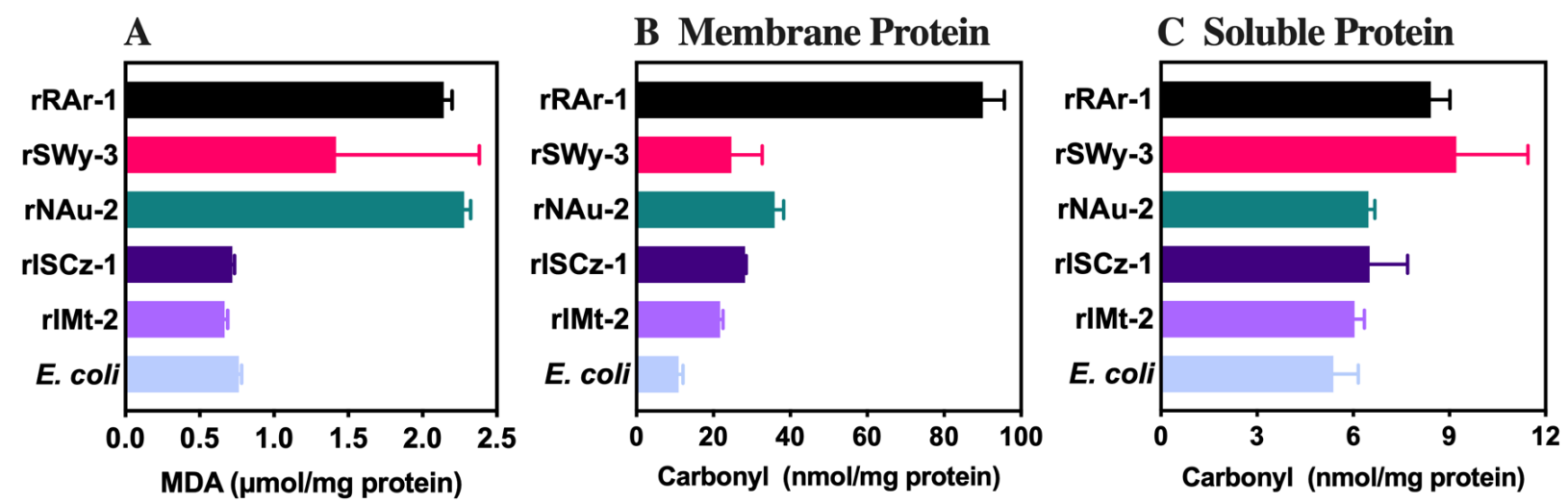

321 Figure S12 (A) Evaluation of membrane lipid peroxidation, measured by the production of

322 malondialdehyde (MDA), after $4 \mathrm{~h}$ treatment by reduced S-I clay minerals. Protein carbonyl

323 content measured in (B) membrane vs. (C) soluble fraction of E. coli cells after clay treatment.

324 Cells without clay exposure were included as a control. Error bars represent standard deviation 325 from triplicate experiments. 


\section{References}

327 1. Amonette, J. E., Improvements to the quantitative assay of nonrefractory minerals for $\mathrm{Fe}(\mathrm{II})$ and total $\mathrm{Fe}$ 328 using 1,10-Phenanthroline. Clays Clay Miner. 1998, 46, (1), 51-62. DOI: 10.1346/ccmn.1998.0460106

$3292 . \quad$ Stookey, L. L., Ferrozine---a new spectrophotometric reagent for iron. Anal. Chem. 2002, 42, (7), 779-781. 330 DOI: 10.1021/ac60289a016

$331 \quad$ 3. Wang, X.; Dong, H.; Zeng, Q.; Xia, Q.; Zhang, L.; Zhou, Z., Reduced iron-containing clay minerals as 332 antibacterial agents. Environ. Sci. Technol. 2017, 51, (13), 7639-7647. DOI: 10.1021/acs.est.7b00726

333 4. Zeng, Q.; Dong, H.; Wang, X., Effect of ligands on the production of oxidants from oxygenation of reduced 334 Fe-bearing clay mineral nontronite. Geochim. Cosmochim. Acta 2019, 251, 136-156. DOI: 10.1016/j.gca.2019.02.032 5. Katsoyiannis, I. A.; Ruettimann, T.; Hug, S. J., pH dependence of Fenton reagent generation and As(III) oxidation and removal by corrosion of zero valent iron in aerated water. Environ. Sci. Technol. 2008, 42, (19), 742430. DOI: $10.1021 / \mathrm{es} 800649 p$

6. Cohn, C. A.; Pak, A.; Strongin, D.; Schoonen, M. A., Quantifying hydrogen peroxide in iron-containing solutions using leuco crystal violet. Geochem. Trans. 2005, 6, (3), 47. DOI: 10.1186/1467-4866-6-47

7. He, J.; Miller, C. J.; Collins, R.; Wang, D.; Waite, T. D., Production of a surface-localized oxidant during oxygenation of mackinawite (FeS). Environ. Sci. Technol. 2020, 54, (2), 1167-1176. DOI: 10.1021/acs.est.9b03975

8. Hug, S. J.; Leupin, O., Iron-catalyzed oxidation of arsenic(III) by oxygen and by hydrogen peroxide: $\mathrm{pH}-$ dependent formation of oxidants in the Fenton reaction. Environ. Sci. Technol. 2003, 37, (12), 2734-2742. DOI: 10.1021/es026208x

9. Lee, H.; Lee, H. J.; Sedlak, D. L.; Lee, C., pH-dependent reactivity of oxidants formed by iron and coppercatalyzed decomposition of hydrogen peroxide. Chemosphere 2013, 92, (6), 652-658. DOI: 10.1016/j.chemosphere.2013.01.073

10. Dong, H. Y.; Li, Y.; Wang, S. C.; Liu, W. F.; Zhou, G. M.; Xie, Y. F.; Guan, X. H., Both Fe(IV) and Radicals Are Active Oxidants in the Fe(II)/Peroxydisulfate Process. Environ Sci Tech Let 2020, 7, (3), 219-224. DOI: 10.1021/acs.estlett.0c00025

11. Zong, Y.; Shao, Y.; Zeng, Y.; Shao, B.; Xu, L.; Zhao, Z.; Liu, W.; Wu, D., Enhanced oxidation of organic contaminants by iron(ii)-activated periodate: The significance of high-valent iron-oxo species. Environ. Sci. Technol. 2021, 55, (11), 7634-7642. DOI: 10.1021/acs.est.1c00375

12. Xia, Q.; Wang, X.; Zeng, Q.; Guo, D.; Zhu, Z.; Chen, H.; Dong, H., Mechanisms of enhanced antibacterial activity by reduced chitosan-intercalated nontronite. Environ. Sci. Technol. 2020, 54, (8), 5207-5217. DOI: 10.1021/acs.est.9b07185

13. Levine, R. L.; Garland, D.; Oliver, C. N.; Amici, A.; Climent, I.; Lenz, A. G.; Ahn, B. W.; Shaltiel, S.; Stadtman, E. R., Determination of carbonyl content in oxidatively modified proteins. Methods Enzymol. 1990, 186, 464-478. DOI: 10.1016/0076-6879(90)86141-h

14. Bishop, M. E.; Dong, H.; Kukkadapu, R. K.; Liu, C.; Edelmann, R. E., Bioreduction of Fe-bearing clay minerals and their reactivity toward pertechnetate (Tc-99). Geochim. Cosmochim. Acta 2011, 75, (18), 5229-5246. DOI: 10.1016/j.gca.2011.06.034 